九州䨑会誌33（4）:376～381， 1979.

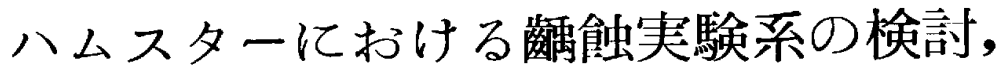 特に萌出期蒾牙に対する影響について
}

九州歯科大学口腔衛生学教室 (主任 : 佐伯榮一教授)

竹原直道・佐 伯榮一

九州大学齒学部予防蒾科学教室 (主任 : 森岡俊夫教授)

古賀 敏比古

昭和54年 9 月 26 日受付

\section{Experimental Dental Caries in Golden Hamsters Effects on the Teeth During Eruption}

\author{
Tadamichi Takehara, Eiichi Saeki \\ Department of Preventive Dentistry (Chief : Prof. Eiichi Saeki) \\ Kyushu Dental College, Kitakyushu, Japan \\ Toshihiko Koga \\ Department of Preventive Dentistry (Chief : Prof. Toshio Morioka) \\ Kyushu University, School of Dentistry, Fukuoka, Japan
}

Cariogenic challenge was effects in the experimental animals of the difference in timing of effecting cariogenic challenge.

The groups with earlier cariogenic challenge showed higher caries scores. With aging, the caries score decreased sharply. On the second molar, what is called "post eruptive maturation" appeared to be continuing even at 37-day-old. With an increase in the intake of sucrose, the caries score increased. Sucrose intake during tooth eruption in particular affects the caries score. Sucrose intake during tooth eruption, even though minute in quantity, has a great influence.

\section{緒畐}

動物の萌出期歯牙に及ぼす樆蝕侵襲の影響を調べた研 究ではラットにおいて増龄により実験滆蝕の発生が抑制 されることが知られており年ら)，同様のととは八ムスタ 一においても言われている6,7). 更には，Streptococcus mutans の歯面への定着もラットに扔いて増柃により低 下するという8，と乙ろで動物を用いた解蝕実験系の成 立には, 基本的に Keyes，P.H.（1969） '9'の提起した 3 条件がそのままあてはまると考えてよい。すなわち，離 蝕原性菌の接種, 鹋蝕誘発性飼料の投与そして歯牙その ものの持つ条件である. 今日ではこれに実験期間の因子
が付け加えられる。しかしながら，実験臹蝕の惹起は， てれらの諸条件の微妙な バランスの頂点に成立してお り，たとえば投与飼料の種類, 投与時期, 投与量等によ って, また接種菌（主にS. mutans）の菌株, 接種時 期, 接種量, 接種期閒等によって実験結果は大きく異っ てくる、したがって，飼料中のある物質（たとえばスク

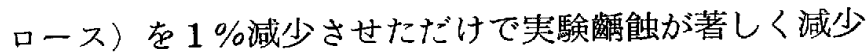

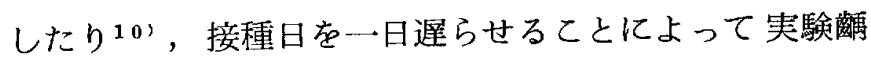
蝕が減少する5゙ などということが起ってくる．すなわ ち, 実験遥蝕の誘発には Keyes の条件がすべてそろう ことが不可欠であるが，一方この実験瀜蝕の抑制または 
減少にはこれらの条件の一つを欠落させることはもちろ ん，乙れらの条件の一部の改変によっても灮験離蝕は成 立しないことになる・本研究では，八ムスタ一の萌出期 蒾牙が一定期間の撂能実験系の成立二漓蝕侵襲，に上り

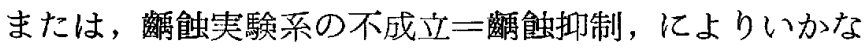
る影響を受けるかを調べるため福蝕誘発性飼料の因子の 有無により実験条件に手を加えることによって以下の実 験を行った。

\section{材 料 と 方 法}

1 ）菌株と培養

実験には Streptococcus mutans AHT-SMR 1 株 ${ }^{11}$ を用いた，同株は硫酸ストレプトマイシン（明治製菓， 東京)，0.2mg/ml培地に耐性であった。この株をBrain Heart Infusion (BBL, Cockeysville, Md., U.S. A.) ブロースで $37^{\circ} \mathrm{C}$ 一夜，嫌気的に $\left(90 \% \mathrm{~N}_{2}+5 \%\right.$ $\mathrm{CO}_{2}+5 \% \mathrm{H}_{2}$ ) 培養した。

\section{2 ) 漓蝕実験}

離乳後, 実験開始まで日農ブリーダMR固型飼料（日 本農産, 横浜) で飼育したゴールデンハムスター12) の

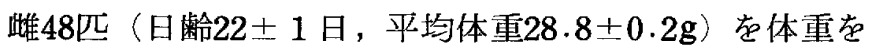
そろえながら任意に 8 匹ずつ6群に分け，各群を同一の ステンレス製金網ケージ入れた。I群を S. mutans 接種，ラット飼育用のM粉末普通飼料（オリエンタル醭 母, 東京) 投与群, II 群を S. mutans 接種, 被蝕誘発 性飼料 diet \#2000 ${ }^{13}$ ）（56\%のスクロースを含む）投 与群とした。群は，日秢26日まで S. mutans 接種， diet \#2000 投与とし，27日よりM粉末飼料に切り換え た。IV群は，日柃26日までM粉末投与，27日より $S$. mutans 接種, diet \#2000 飼料に切り換えた。V群は, 日龄36日まで S. mutans 接種, diet \#2000 投与し， 37日よりM粉末飼料に切り換えた。VI群は，日龄36日ま でM粉末飼料投与，37日より S. mutans 接 種, diet \#2000 飼料に切り換えた。飼料ならびに 飲料水（脱イ オン水) は自由に摄取させ，また飼料の恸取量（給餌器 からの脱落量を含む）を記録した．また，S. mutansの 接種は上記培養液 $0.2 \mathrm{ml}$ 芷ピペットで八ムスターの口腔 内に滴下した。接種は，1日 1 回，2日間行った。茵牙 萌出期における一定条件下の離蝕侵襲が成長した同日齢 のハムスターに及ぼす影響を調べるという目的のため， ハムスターを日噛65日で同時に屠殺した。 以上の実験の プロトコールをFig. 1亿示した・尚, ハムスターの飼育 はバイオトロン (温度 $20^{\circ} \mathrm{C}$, 湿度 $60 \%$, 昼光 12 時間/日) で行った。

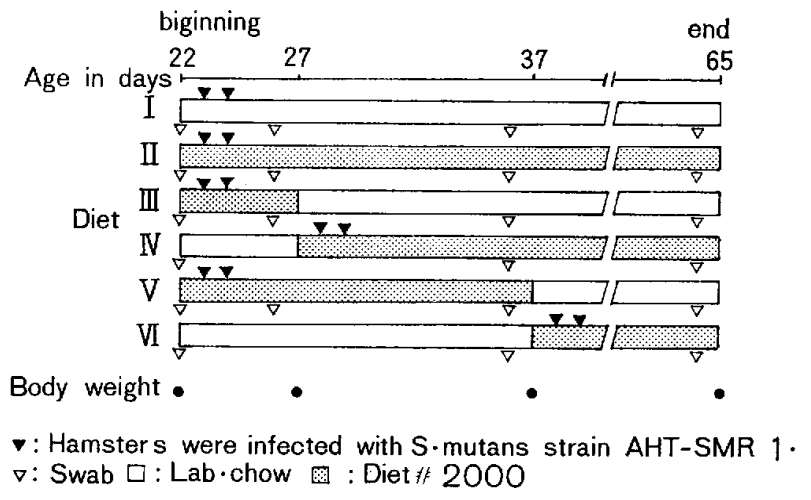

Fig. 1 Design of the experiment in golden hamsters.

3 ）旅蝕と蒾苔の評価および細菌検查

八ムスターをエーテル屠殺し，顝骨を摘出した後，曰 歯部菊苔染色液 (Butler Co. Chicago, U.S. A.) で染色し，各臼歯の煩・舌（口蓋）面に付着した歯苔を $0 \sim 3 の 4$ 段階で評価した。 この後, 䫓骨をオートクレ ーブして軟組織を剝離，乾燥させ，日歯に生じた䀞蝕を Keyes ${ }^{14}$ 'の方法に準じて評価した。尚，本実験の結果 はすべて Mann-Whitney の順位和法 ${ }^{15}$ 用いて検討 した。

口腔よりのS. mutans の検出には，八ムスターの上 顎臼蒾を 減菌綿棒でスワブし, $2 \mathrm{~m} 1$ の 減菌生食水に懸 濁後, その $0.1 \mathrm{~m} 1$ を $0.2 \mathrm{mg} / \mathrm{m} 1$ 培地のストレプトマイシ ンを含む Mitis salivarius 培地 (Difuco, Detroit, U.S.A.MS-SM培地) に接種し, 嫌気的に $37^{\circ} \mathrm{C} 2$ 日間培 養した.S. mutansは，色素のとり乙みの良い，岩様状 の培地にくいてんだ集落を計数したが，疑わしいものに ついては，更に試験管壁付着能の有無 ${ }^{11}$ を検討し，同定 した。得られた集落数をもとにスワブ生食水 $0.1 \mathrm{ml}$ 当り の集落形成単位数をー〜 4+の6 段階で表示した。 ${ }^{16}$ )

\section{結果}

1 ) 八ムスター歯牙の萌出状態

普通飼育のゴールデンハムスター（雌）の日齢22日， 27日，65日における歯牙の萌出状態を示す歯牙標本を

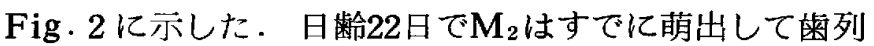
に並んでいるが， $\mathrm{M}_{3}$ は日腔内に露出していない，日齢 27日においても基本的に同様である.日㱓65日ではすべ てのハムスター曰歯が萌出し終えていた。

2 ) 脐蝕之歯苔の形成

結果を Table 1 にまとめて示した，実験開始前拉よ び S. mutans 接種前においては, 調べた限りにおいて 
Table 1 Caries development and plaque formation in golden hamsters.

\begin{tabular}{|c|c|c|c|c|c|c|c|c|c|c|c|}
\hline \multirow[b]{3}{*}{$\begin{array}{l}\text { Exp. } \\
\text { group }\end{array}$} & \multirow[b]{3}{*}{$\begin{array}{l}\text { No. of } \\
\text { aimals }\end{array}$} & \multirow{3}{*}{$\begin{array}{l}\text { Body } \\
\text { weight } \\
\text { gain } \\
\text { (g/ } \\
\text { animal })\end{array}$} & \multirow{2}{*}{\multicolumn{3}{|c|}{$\begin{array}{l}\text { Intake of diet } \\
\text { (g/animal) }\end{array}$}} & \multicolumn{4}{|c|}{ Tooth decay (/animal) } & \multirow{3}{*}{$\begin{array}{l}\text { Plaque } \\
\text { score } \\
\text { (/animal) }\end{array}$} & \multirow{3}{*}{$\begin{array}{c}\text { Recovery* } \\
\text { of } \\
\text { S. mutans } \\
\left(\begin{array}{c}64 \text { day } \\
\text { MS-SM } \\
\text { agar }\end{array}\right)\end{array}$} \\
\hline & & & & & & \multirow{2}{*}{$\begin{array}{l}\text { No.of } \\
\text { caries } \\
\text { teeth }\end{array}$} & \multirow{2}{*}{$\begin{array}{l}\text { Caries } \\
\text { surface } \\
\text { score }\end{array}$} & \multirow{2}{*}{$\begin{array}{l}\text { Caries } \\
\text { score }\end{array}$} & \multirow[b]{2}{*}{ (range) } & & \\
\hline & & & $\begin{array}{l}\text { Lab. } \\
\text { chow }\end{array}$ & $\begin{array}{l}\text { Diet } \\
\# 2000\end{array}$ & (sucrose) & & & & & & \\
\hline $\mathbf{I}$ & 8 & 60 & 456 & 0 & 0 & 0.4 & 0.13 & 0.13 & $(0-0.5)$ & 24 & - \\
\hline II & 8 & 58 & 0 & 358 & 200 & 9.4 & 16.0 & $24 \cdot 3$ & $(13 \cdot 3-36)$ & $34 \cdot 4$ & thit \\
\hline III & 8 & 59 & 454 & 25 & 14 & 0.4 & 0.13 & 0.13 & $(0-0.5)$ & 24.9 & \pm \\
\hline IV & 8 & 52 & 41 & 322 & 180 & 8.0 & 12.3 & 16.4 & $(4 \cdot 3-35 \cdot 3)$ & 29.6 & HIt \\
\hline V & 8 & 56 & 331 & 82 & 46 & 3.4 & 1.60 & 1.63 & $(0.5-3.3)$ & $24 \cdot 5$ & \pm \\
\hline VI & 8 & 65 & 156 & 254 & 1.42 & 3.0 & 1.80 & 1.81 & $(0-5 \cdot 3)$ & 24 & H \\
\hline
\end{tabular}

* Colony forming units per $0.1 \mathrm{ml}$ of swab's saline :

- , no colony ;,$\pm<50 ;+, 50 \sim 250 ; H, 250 \sim 500 ; \mathrm{H}, 500 \sim 1,000 ; \mathrm{Ht},>1,000$

八ムスター口腔内には S. mutans は全く検出できなか った。接種したS. mutans はI群において日秢26日の リカバーでわずかに見られたが，36日ではすでに姿を消 していた（成績省略）。日柃64日におろいてリカバーした
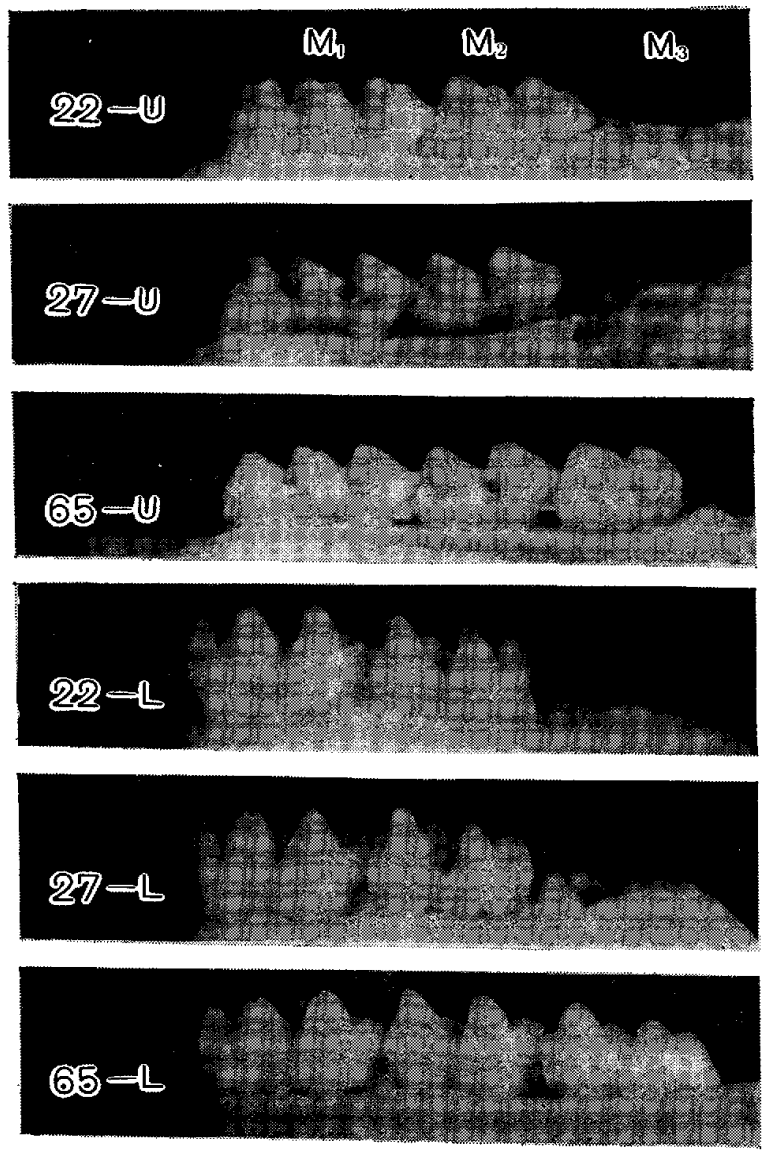

Fig. 2 Photographs of teeth of golden hamsters at different ages. The numbers indicate post natal age of the hamster in days.

U:Upper jaw, L:Lower jaw
S. mutans の集落数は, 実験終了時に普通飼料摂取群 ( I , III，V群) で少く, diet \#2000 掑取群（II， IV， VI群)で多かった。

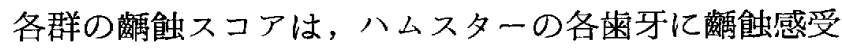
性に差がある12，17ー19) ことを考慮に入れて，Table 2 に各蒾別の龋蝕スコアを示し，さらに，統計妈理の結果 を Table 3 に示した. Table 1，2の結果をわかりや すくするため，横軸に diet \#2000中に含まれるスクロ 一スの摂取量を, 縦軸に融蝕スコアをとって図に表わし た (Fig. 3). 璃蝕スコアはS. mutans 接種, 全実験 期間中 diet \#2000 提取群（II群）が最も高く， diet \#2000 摂取量が 0 かまたは少く，かつ提取期間が短い 群（I，III群）において最も低かった。I群と III群で は，S. mutansの接種あるいは短期閒の diet $\# 2000 の$ 搷取はその唃蝕スコアに影響を与えず統計学的に有意な

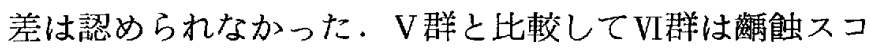
アはほば同程度であったが，スクロースの掑取量は 3 倍 多く，またV群では $\mathrm{M}_{3}$ のスコアが高いのに較べてV群 では $\mathrm{M}_{2}$ のスコアが高かった。また，V群はV群に較心゙ て罇蝕スコアにバラッキが大きくI， III群との間に有意 な差は見られなかった。II群とIV群では，スクロース提 取量では差はあまりないが(日数でも 5 日聞) スコアは， 1.5倍であった（もっとも有意な差はない）．結局Ｉ・II 群と V 群, I・III・V・VI群と II ・ IV 群の間に有意な差 が存在することがわかった，II，IV，VI群の間で見る

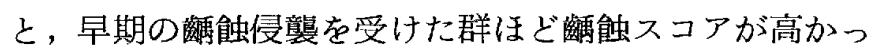
た。一方菌牙別の触蝕スコアについて見てみると， $\mathrm{M}_{1}$ についてはすべての群に有意差がなく， $\mathrm{M}_{2}, \mathrm{M}_{3}$ は総敵 蝕スコアとほぼ同様の結果を示した。もっとも， I-V 群，III-V群については $\mathrm{M}_{3}$ に有意差はなく, IV-V群に ついは $\mathrm{M}_{2}$ に有意差がなかった（Table 3 ）。 
Table 2 Caries score of individual molars of golden hamsters.

\begin{tabular}{clccccc}
\hline $\begin{array}{c}\text { Exp. } \\
\text { group }\end{array}$ & $\underline{\mathrm{M}_{1}}$ & $\underline{\mathrm{M}_{2}}$ & $\underline{\mathrm{M}_{3}}$ & $\overline{\mathrm{M}_{1}}$ & $\overline{\mathrm{M}_{2}}$ & $\overline{\mathrm{M}_{3}}$ \\
\hline I & 0 & 0.03 & 0 & 0 & 0 & 0.09 \\
II & 0.28 & 4.97 & 8.09 & 1.16 & 2.81 & 6.94 \\
III & 0 & 0.06 & 0 & 0 & 0 & 0.06 \\
IV & 0.25 & 1.84 & 5.97 & 0.72 & 2.38 & 5.25 \\
V & 0 & 0.63 & 0.09 & 0.03 & 0.72 & 0.16 \\
VI & 0 & 0.22 & 0.66 & 0 & 0.19 & 0.75 \\
\hline
\end{tabular}

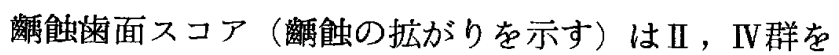

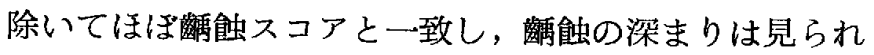

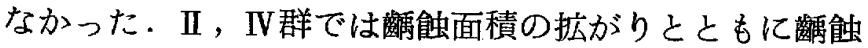
の深度も増加した。

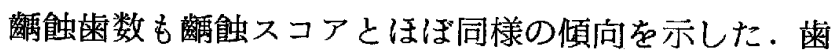
苔スコアも滆蝕スコアとほぽ同様の傾向を示したが，で く僅かの米苔形成をもすべて +1 として評価するという 方法上の問題点もあって，各群間の差ははっきりしなく なる傾向があった。

これらのことからみて, diet \#2000 ひいてはスクロ 一スの摂取量が多ければ睞蝕スコアが増大するという関 係を示したが，その摂取時期により大きな差が存在し，

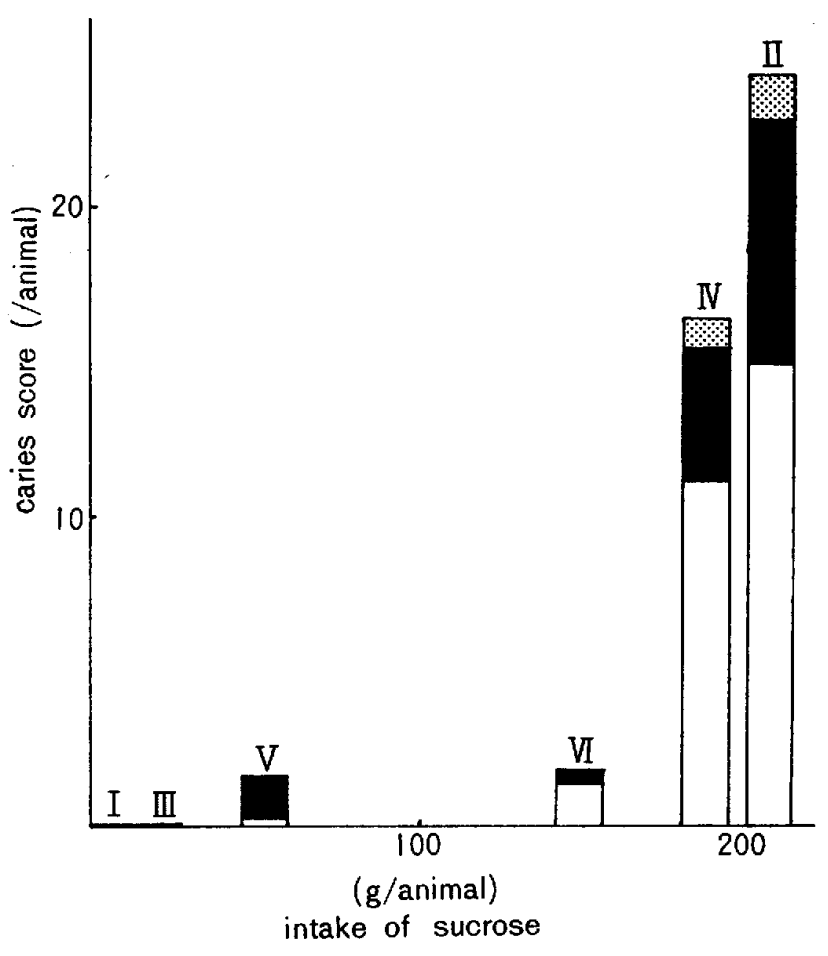

冈: $M_{1} \square: M_{2} \square: M_{3}$

Fig. 3 Comparative analyses of caries score and intake of sucrose.

Table 3 The comparison of statistically significance of caries score and plaque score between experimental groups.

\begin{tabular}{|c|c|c|c|c|c|c|c|c|c|c|}
\hline & \multicolumn{7}{|c|}{ Caries score } & \multirow{2}{*}{$\begin{array}{l}\text { Caries } \\
\text { surface } \\
\text { score }\end{array}$} & \multirow{2}{*}{$\begin{array}{l}\text { No.of } \\
\text { caries } \\
\text { teeth }\end{array}$} & \multirow{2}{*}{$\begin{array}{l}\text { Plaque } \\
\text { score }\end{array}$} \\
\hline & $\underline{\mathbf{M}_{1}}$ & $\underline{\mathbf{M}_{2}}$ & $\underline{\mathrm{M}_{3}}$ & $\overline{\mathrm{M}_{1}}$ & $\overline{\mathbf{M}_{2}}$ & $\overline{\mathbf{M}_{3}}$ & Total & & & \\
\hline $\begin{array}{l}I-I I \\
I-I I I\end{array}$ & & $* * *$ & $* * *$ & & $* * *$ & $* * *$ & $* * *$ & $* * *$ & $* * *$ & $* * *$ \\
\hline I - IV & & $* *$ & $* * *$ & & $*$ & $* * *$ & $* * *$ & $* * *$ & $* * *$ & $* * *$ \\
\hline $\begin{array}{l}I-V \\
I-V I\end{array}$ & & & & & $*$ & & $* * *$ & $* * *$ & $* * *$ & \\
\hline $\begin{array}{l}\text { II - III } \\
\text { II -IV }\end{array}$ & & $* * *$ & $* * *$ & & $* * * k$ & $* * *$ & $* * *$ & $* * *$ & $* * * *$ & $\begin{array}{l}* * * \\
*\end{array}$ \\
\hline II - V & & $* * *$ & $* * *$ & & $* *$ & $* * *$ & $* * *$ & $* * *$ & $* * *$ & $* * *$ \\
\hline II - VI & & $* * *$ & $* * *$ & & $* * *$ & $* * *$ & $* * *$ & $* * * *$ & $* * *$ & $* * *$ \\
\hline III -IV & & $* *$ & $* * *$ & & $* * *$ & $* * *$ & $* * *$ & $* * *$ & $* * * *$ & * \\
\hline $\begin{array}{l}\text { III - V } \\
\text { III - VI }\end{array}$ & & & & & $*$ & & $* * *$ & $* * *$ & $* * *$ & \\
\hline $\mathrm{IV}-\mathrm{V}$ & & & $* * *$ & & & $* * *$ & $* * *$ & $* * *$ & $* * *$ & $* *$ \\
\hline $\begin{array}{l}\mathrm{IV}-\mathrm{VI} \\
\mathrm{V}-\mathrm{VI}\end{array}$ & & $*$ & $* * *$ & & $* *$ & $* * *$ & $* * *$ & $* * *$ & $* *$ & $* * *$ \\
\hline
\end{tabular}

Statistically significance ${ }^{*}(\mathbf{p}<0.05),{ }^{* *}(\mathbf{p}<0.02),{ }^{* * *}(\mathbf{p}<0.002)$ 
スクロース摂取量と離蝕スコアの間には直線関係は得ら れなかった。

\section{考察}

本研究では Keyes の 3 条件の充足をもって数蝕侵襲 が始めて成立するという前提をもうけ，その前提のもと に以上の実験を行ってきた，以下てれらの実験の結果に ついて若干の検討を加えることにしたい，最初にS. mutans の接種はFig. 1 に示すように，I群を除き diet \#2000 投与の 2 日目と 3 日目に行った。したがっ て Keyesの 3 条件がそろうのは，たとえばII群の場合 では日秢23日ということになる。一方，I群において は，S. mutansの接種のみでは Keyes に上る裙蝕侵襲 の条件を満しておらず Table 1 の結果から見ても菌の 接種でけでは酮蝕侵襲は成立しないと思われる。しかし ながらスクロースをグルコースまたはでんぷんに変えた 飼料での S. mutans の接種の有無により褾蝕スコアを 調べた Fitzgerald, et al. $(1972)^{20}$ の実験では, 非 接種群のスコアは接種群より少い結果が示されており， 極めて 微量の変化ながら S. mutans 非接種, 普通飼料 飼育群を想定した場合，乙の想定群とＩ群あるいは群 との間の酮蝕スコアに有意の差が生ずる可能性は否定で きない。

次に本実験では非酩蝕誘発性飼料として計量の便をは

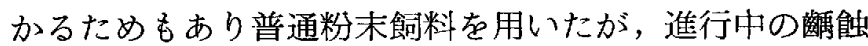
を停止させるという目的からはむしろ固型飼料の方がよ いと思われる。しかしながらV群とII，IV群の間に有意 差があるととから見て普通粉末飼料においても十分進行 中の䡒蝕を停止させていると思われた．

次に菌牙の萌出状態は Fig. 2 に示した如く 日秢27日 までは $\mathrm{M}_{3}$ は萌出しておらず，たと光ば $\mathrm{M}_{3}$ に限ってみれ ば II -IV 群間の踊蝕スコアには差はない。一方，IV-VI群 間には有意差が存在し，乙の間10日間の差が $\mathrm{M}_{3}$ の桶蝕 スコアにして約 8 倍の差として表われている。乙の間に $\mathrm{M}_{3}$ の萌出が予測される ${ }^{21}$ 乙とから歯牙萌出直後の僃蝕 侵襲は極めて大きな影響をその菌牙に与えることが示唆 される.さらにいわゆる“post eruptive maturation” を想定した場合， $\mathrm{M}_{2}$ についてV群の颜蝕スコアがVI群 のそれより高いことから見て日料12〜14日の間に萌出し た $\mathrm{M}_{2}$ の "post eruptive maturation"は少くとも日柃 37日の段階まで続いているととが推定される。したがっ

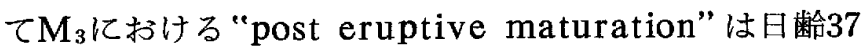
日以後に引き続き存在するのであろう。また眪蝕侵襲の 期間を一定にするという，Schuster, et al. $(1978)^{5}$ ),
Larson, et al. $(1964)^{2)}$, Navia, et al. $(1977)^{4)}$ の 方法をとらず同日秢での屠殺を行うことにより Fig. 3 に示したように菌牙萌出期に摂取した酮蝕誘発性餜料, ひいてはスクロースの量と蕾蝕スコアの関係を示し得る と思われる.すなわち，一定日秢（この場合65日秢）に

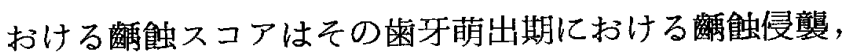
なかんずくスクロースの掑取によって影響され，㐘牙の 萌出時期においては, 微量のスクロース量によっても， その 䤍蝕スコアに強い影響を与えると思われるのであ る.

\section{結論}

ハムスターの柬牙萌出期に時期を変えて，S. mutans の接種と酮蝕誘発性飼料投与による脐蝕侵襲を行うこと により以下の結果を得た。

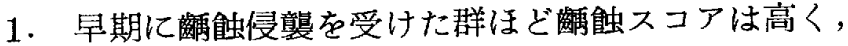
加齢とともに，䙵蝕スコアは急激に減少した。

2. 日秢37日の段階で $\mathrm{M}_{2}$ のいわゆる "post eruptive maturation"が続いていると思われた.

3. スクロースの摄取量が増加すると瀜蝕スコアも增加 した。

4. しかしながら畨牙萌出期におけるスクロースの摄取 が颜蝕スコアに影響を与えており，萌出期のスクロー ス摃取は微量でも大きな影響力を持つととがわかっ た。

5. 同様の䈏蝕実験系における実験上の諸条件について 考察した。

\section{文献}

1) Madsen, K. O. and Edmonds, E. J. : Use of twelve day-old cotton rats for dental caries studies, $J$. Dent. Res. $42: 867-873$, 1963.

2 Larson, R. H. and Fitzgerald, R. J. ; Caries development in rats of different ages with controlled flora, Archs. oral Biol. 9:705-712, 1964 .

3 ) 大西正男, 尾崎文子・他 : ラットの歯牙年柃と St. mutans 感染に対するラットの抵抗增加, 口腔衛生会誌. $23: 116-117,1973$.

4 ) Navia, J. M. and Lopez, H. : Sources of variability in rat caries studies: weaning age and diet fed during tooth eruption, J. Dent. Res. $56: 222-227,1977$. 
5 Schuster, G.S., Morse, P.K., et al.: Interaction of microbial challenge and age at inoculation in the production of dental caries in rats, Caries Res. 12:28-34, 1978.

6) Sognnaes, R.F. : Caries-conducive effect of a purified diet when fed to rodents during tooth development, J. Am. Dent. Ass. $37: 676-686,1948$.

7 ) Volker, J. F. and Klapper, C. E. : Some observations on dental caries in syrian hamsters, O. Surg. O. Med. O. Path. $7: 207-212$, 1954 .

8 ) van Houte, J., Upeslacis, V. N. et al. : Decreased oral colonization of Streptococcus mutans during aging of spraguedawley rats, Infect. Immun. $16: 203-212$, 1977.

9) Keyes, P. H. : Present and future measures for dental caries control, J. Am. Dent. Ass. 79: 1395-1404, 1969.

10) Michalek, S.M., Mcghee, J.R., et al. : Low sucrose levels promote extensive Streptococcus mutans-induced dental carjes,

Infect. Immun. 16:712-714, 1977.

11）古賀敏比古, 井上昌一：Streptococcus mutans AHT 株の管壁付着能変異株の分離と性状，雨 科基礎誌. $19: 117-127,1977$.

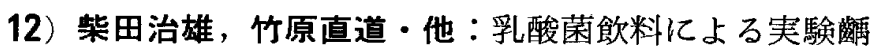
蝕の重症化，口腔衛生会誌. $27 ： 46-57,1977$.

13) Keyes, P. H. and Jordan, H.V. : Periodontal lesions in the syrian hamster, III .Findings related to an infectious and transmissible component, Archs. oral Biol. $9: 377-400$, 1964 .

14) Keyes, P. H. : A method of recording and scoring gross carious lesions in the molar teeth of syrian hamsters, J. Dent. Res. $23: 439-444,1944$.

15) Mann, H. B. and Whitney, D. R. : On a test of whether one of two random variables in stochastically larger than the other, Ann. Math. Satist. 18:50-60, 1947.

16) Keyes, P. H. and Fitzgerald, R. J. : Dental caries in the syrian hamster-IX, Archs. oral Biol. 7 : 267-278, 1962.

17) Keyes, P. H. : Dental caries in the syrian hamster-VII. The induction of rampant caries activity in albino and golden animals, J. Dent. Res. 38:525-533, 1959.

18) Fitzgerald, R. J., Keyes, P. H. et al.: The effects of a dextranase preparation on plaque and caries in hamsters, a preliminary report, J. Am. Dent. Ass. 76 : 301-304, 1968 .

19）大杉利幸, 柴田治椎・他：ハムスタ一実験系におけ る歯苔形成，瀜蝕ならびに歯槽骨吸収のStreptomyces globisporus 由来の溶菌酵素による抑 制, 口腔衛生会誌, $24: 365-372,1974$.

20) Fitzgerald, D. B. and Fitzgerld, R. J. : Intermittent sucrose feeding and caries in hamsters, Archs, oral Biol. $17: 215-$ 217,1972 .

21) Orland, F. J., : A study of the syrian hamster, its molars, and their lesions, J. Dent. Res. 25 : 445-453, 1946. 